Research paper

\title{
Synergistic inhibition of the Hedgehog pathway by newly designed Smo and Gli antagonists bearing the isoflavone scaffold
}

\author{
Simone Berardozzi ${ }^{\text {a, b, 1,2 }}$, Flavia Bernardi ${ }^{c, 2}$, Paola Infante ${ }^{\mathrm{b}}$, Cinzia Ingallina ${ }^{\mathrm{a}}$, \\ Sara Toscano a , Elisa De Paolis ${ }^{\text {a, b}}$, Romina Alfonsi ${ }^{c}$, Miriam Caimano ${ }^{\mathrm{c}}$, Bruno Botta ${ }^{\text {a }}$, \\ Mattia Mori ${ }^{b, *}$, Lucia Di Marcotullio ${ }^{c, d, * *}$, Francesca Ghirga ${ }^{\text {b }}$ \\ a Department of Chemistry and Technology of Drugs, Sapienza University of Rome, Piazzale Aldo Moro 5, 00185 Rome, Italy \\ ${ }^{\mathrm{b}}$ Center for Life Nano Science@Sapienza, Istituto Italiano di Tecnologia, Viale Regina Elena 291, 00161 Rome, Italy \\ c Department of Molecular Medicine, Sapienza University of Rome, Viale Regina Elena 291, 00161 Rome, Italy \\ ${ }^{\mathrm{d}}$ Istituto Pasteur-Fondazione Cenci Bolognetti, Sapienza University of Rome, 00161 Rome, Italy
}

\section{A R T I C L E I N F O}

\section{Article history:}

Received 23 May 2018

Received in revised form

25 June 2018

Accepted 7 July 2018

Available online 9 July 2018

\section{Keywords:}

Hedgehog inhibitors

Synergistic effects

Isoflavones

Cancer

Smo antagonists

Gli inhibitors

\begin{abstract}
A B S T R A C T
Aberrant activation of the Hedgehog (Hh) pathway is responsible for the onset and progression of several malignancies. Small molecules able to block the pathway at the upstream receptor Smoothened (Smo) or the downstream effector Gli1 have thus emerged recently as valuable anticancer agents.

Here, we have designed, synthesized, and tested new Hh inhibitors taking advantage by the highly versatile and privileged isoflavone scaffold. The introduction of specific substitutions on the isoflavone's ring $\mathrm{B}$ allowed the identification of molecules targeting preferentially Smo or Gli1. Biological assays coupled with molecular modeling corroborated the design strategy, and provided new insights into the mechanism of action of these molecules. The combined administration of two different isoflavones behaving as Smo and Gli antagonists, respectively, in primary medulloblastoma (MB) cells highlighted the synergistic effects of these agents, thus paving the way to further and innovative strategies for the pharmacological inhibition of Hh signaling.
\end{abstract}

(c) 2018 Elsevier Masson SAS. All rights reserved.

\section{Introduction}

The Hedgehog ( $\mathrm{Hh}$ ) pathway is a signaling cascade that plays a crucial role in embryonic development and tissue homeostasis $[1,2]$. Although in adults Hh signaling is activated during tissue repairing and wound healing, its aberrant activation has been reported to drive tumorigenesis and tumor progression in several cancers [3]. Germline or somatic mutations of genes encoding Hh pathway components have been identified in human and murine basal cell carcinoma (BCC) and medulloblastoma (MB) [4-6]. Moreover a growing number of reports correlate uncontrolled $\mathrm{Hh}$

\footnotetext{
* Corresponding author.

** Corresponding author. Department of Molecular Medicine, Sapienza University of Rome, Viale Regina Elena 291, 00161 Rome, Italy.

E-mail addresses: mattia.mori@iit.it, m.mattia79@gmail.com (M. Mori), lucia. dimarcotullio@uniroma1.it (L. Di Marcotullio).

1 Present address: Department of Chemistry and Applied Biosciences, ETH-Zürich, Vladimir-Prelog-Weg 1-5/10, 8093 Zürich, Switzerland.

${ }^{2}$ SB and FB equally contributed to this work.
}

signaling with multiple cancers such as lung, breast, stomach, pancreas, ovarian carcinoma and hematopoietic malignancies [5,7-10]. Targeting the Hh signaling pathway with small molecule modulators has thus emerged as a profitable anticancer strategy, as also highlighted in recent reviews [11-15]. The largest part of $\mathrm{Hh}$ modulators developed so far act as antagonists of the upstream Smoothened receptor (Smo) [16-20], whereas only a few inhibitors of the downstream effectors Glioma-associated oncogene homologue (Gli) proteins have been disclosed, most of which acting by an unclear or indirect mechanism of action [12,21-24]. Two Smo antagonists, namely Vismodegib and Sonidegib, have been approved by the Food and Drug Administration (FDA) in 2012 and 2015, respectively, for the treatment of metastatic and locally advanced BCC, while a number of additional Smo antagonists are currently undergoing clinical evaluation [19,20,25]. However, the emergence of drug-resistance [15,26-29], and the occurrence of aberrant $\mathrm{Hh}$ activation downstream of Smo seriously limited the use of these drugs, and raised some concerns on the efficacy of therapeutic approaches that target Smo. Indeed, pharmacological modulation of the final and most powerful effector Gli1 is nowadays considered 
a more efficient - although challenging - strategy to block Hh signaling in cancer [12]. However, only the Gli antagonist Arsenic trioxide (ATO) has entered clinical evaluation so far [30]. It is therefore widely accepted that novel Hh inhibitors acting through different mechanisms of action than Smo antagonism, or able to overcome drug resistance, are in high demand as therapeutic candidates for the treatment of Hh-dependent tumors.

A significant contribution to the discovery of novel Hh inhibitors is given by natural compounds $[11,17,22,31,32]$. The first Hh inhibitor ever discovered has been Cyclopamine, a steroidal alkaloid isolated from plants of the Veratrum species [13,33]. Subsequently, many natural compounds belonging to different chemical classes have been identified and characterized as Hh inhibitors acting through different mechanisms [11]. Of particular interest is the case of isoflavones, a class of natural compounds particularly abundant in plants of the Leguminosae family. The isoflavone nucleus consists of two phenyl rings linked by a pyran ring to form an oxygenated heterocyclic ring, resulting in the typical 15 carbon atoms (C6-C3C6) skeleton with three rings, labeled A, B and C (Fig. 1). Isoflavones have long received attention due to their interesting biological activity and multiple benefits to human health [34-36]. Furthermore, isoflavones have emerged as privileged structures for Hh inhibition in multiple and independent works. The phytoestrogen Genistein (Fig. 1) has been first shown in 2010 to inhibit Hh signaling in prostate cancer cells in vitro and in vivo either as food supplement in combination with other flavonoids or as isolated compound [37]. Then, several studies pinpointed the role of Genistein as $\mathrm{Hh}$ inhibitor, showing particular efficacy against cancer stem cells (CSCS) of prostate [38], gastric [39], and breast cancer [40], even though its macromolecular target has not been elucidated yet. In contrast, Daidzein (Fig. 1) has been found to suppress Gli1 activation in human breast cancer cells by inhibiting the tumor necrosis factor- $\alpha$ (TNF- $\alpha$ ), which is known to activate Hh signaling by enhancing Gli1 nuclear translocation and transcriptional activity [41]. Recently, by screening a natural compounds library, our research group has identified the prenylated isoflavone Glabrescione B (GlaB, Fig. 1) as direct inhibitor of Gli1/DNA interaction endowed with significant anticancer efficacy in vitro and in vivo against Hh-dependent MB and BCC [22]. The mechanism of action of GlaB has been deeply characterized at the molecular level, thus

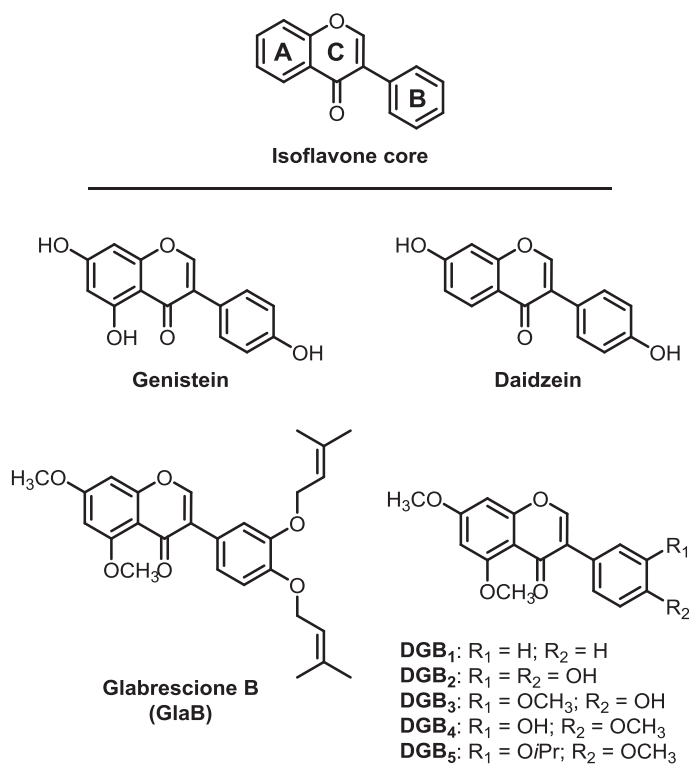

Fig. 1. Chemical structure of isoflavones that have been previously investigated as $\mathrm{Hh}$ inhibitors. pointing to the druggability of Gli1/DNA interaction in the treatment of Hh-dependent tumors. Moreover, chemical modifications at the ring B of GlaB (Fig. 1) proved not effective in Hh inhibition. This data highlights preliminary structure-activity relationships (SAR) of GlaB, and identifies the relevant molecular determinants for the inhibition of Gli1 binding to DNA and related transcriptional activities.

Based on these evidences, here we exploit the versatility of the isoflavone scaffold as well as its affinity for the Hh signaling pathway with the aim to design, synthesize and test specific Smo or Gli antagonists. We combined computational modeling, organic synthesis, and biological evaluations in a concerted multidisciplinary strategy. Chemical derivatives sharing the isoflavone core were designed and screened in silico against the 3D structure of Smo and Gli1 available by X-ray crystallography studies [42-45]. A new and more efficient route to synthesize these isoflavones was established; selected compounds were tested for their functional and biological efficacy. Since several current clinical studies on Hh inhibitors are designed to test a combination between a FDAapproved Smo antagonist and a cytotoxic anticancer agent (i.e. Sonidegib in combination with Etoposide and Cisplatin, clinicalTrial.gov identifier: NCT01579929), here we monitored for the first time the synergistic effect of the combination between two targeted isoflavones acting specifically at Smo or Gli.

Further, and yet unexplored, approaches to target the $\mathrm{Hh}$ signaling pathway might be stimulated by this work, including the design of multi-target $\mathrm{Hh}$ inhibitors according to the fashionable polypharmacology principles.

\section{Materials and methods}

\subsection{Chemistry}

All non-aqueous reactions were performed under an argon atmosphere using flame-dried glassware and standard syringe/septa techniques.

All absolute solvents were purchased as anhydrous grade from Sigma Aldrich and used without further purification unless otherwise stated. Solvents for extractions, flash column chromatography (FC) and thin layer chromatography (TLC) were purchased as commercial grade from Sigma Aldrich and used without further purification unless otherwise stated. Reactions were magnetically stirred and monitored by TLC performed on Merck TLC aluminum sheets (silica gel 60 F254). Spots were visualized with UV light $(\lambda=254 \mathrm{~nm})$. Chromatographic purification of products (FC) was performed using Sigma Aldrich silica gel 60 for preparative column chromatography (particle size $40-63 \mu \mathrm{m}$ ). Melting points (Mp) were obtained in open capillary tubes using a Büchi melting point apparatus B-545 and are uncorrected. ${ }^{1} \mathrm{H}$ and ${ }^{13} \mathrm{C}$ NMR spectra were recorded in $\mathrm{CDCl}_{3}$, acetone- $d_{6}$, DMSO- $d_{6}$ or methanol- $d_{4}$ on a Bruker AV-400 $400 \mathrm{MHz}$ spectrometer (operating at $400 \mathrm{MHz}$ for ${ }^{1} \mathrm{H}$ and $100 \mathrm{MHz}$ for ${ }^{13} \mathrm{C}$ ) at room temperature and tetramethylsilane (TMS) as internal standard. Chemical shifts $(\delta)$ are reported in parts per million (ppm) and are referenced to $\mathrm{CHCl}_{3}(\delta=7.26 \mathrm{ppm}$ for ${ }^{1} \mathrm{H}, \delta=77.16 \mathrm{ppm}$ for $\left.{ }^{13} \mathrm{C}\right)$, acetone $\left(\delta=2.05 \mathrm{ppm}\right.$ for ${ }^{1} \mathrm{H}$, $\delta=29.84 \mathrm{ppm}$ for $\left.{ }^{13} \mathrm{C}\right)$ DMSO $\left(\delta=2.50 \mathrm{ppm}\right.$ for ${ }^{1} \mathrm{H}, \delta 39.52 \mathrm{ppm}$ for $\left.{ }^{13} \mathrm{C}\right)$, or $\mathrm{MeOH}\left(\delta=3.31 \mathrm{ppm}\right.$ for ${ }^{1} \mathrm{H}, \delta 49.00 \mathrm{ppm}$ for $\left.{ }^{13} \mathrm{C}\right)$. All ${ }^{13} \mathrm{C}$ NMR spectra were measured with complete proton decoupling. Data for NMR spectra are reported as follows: $s=$ singlet, $\mathrm{d}=$ doublet, $\mathrm{t}=$ triplet, $\mathrm{q}=$ quartet, $\mathrm{m}=$ multiplet, $\mathrm{br}=$ broad signal, $J=$ coupling constant in Hz. High-resolution mass spectra (HRMS) were recorded on Bruker BioApex Fourier transform ion cyclotron resonance (FT-ICR) mass spectrometer. HPLC analysis was performed on a Waters 2690 Separation Module, equipped with a Rheodyne Model 8125 20- $\mu \mathrm{L}$ injector and a Model M486 
programmable multi-wavelength detector (PDA). Chromatographic data were collected and processed using the Empower Chromatography Manager software. Column: Phenomenex Luna C18, $5 \mu \mathrm{m}$ $(250 \times 4.6 \mathrm{~mm})$; eluent A) $\mathrm{H}_{2} \mathrm{O} / \mathrm{CH}_{3} \mathrm{CN}, 95: 5 \mathrm{v} / \mathrm{v}$, eluent B) $\mathrm{H}_{2} \mathrm{O} /$ $\mathrm{CH}_{3} \mathrm{CN}$, 5:95 v/v; gradient elution: for $0-5 \mathrm{~min} \mathrm{~A}: \mathrm{B}=50: 50$; $5-20$ min up to $100 \% \mathrm{~B} ; 20-25 \mathrm{~min}$ to $100 \% \mathrm{~B}$; flow rate: $1.0 \mathrm{~mL} /$ min; UV detection at $295 \mathrm{~nm}$. The purity of the compounds was always higher than $95 \%$.

General procedure for the preparation of deoxybenzoines (3a-d). In a two-neck round-bottom flask a mixture of 3,5dimethoxyphenol (1) (6 mmol, 1.00 equiv.), 3,4-disubstitutedphenylacetic acid (2a-d) (6 mmol, 1.00 equiv.) and $\mathrm{BF}_{3} \bullet \mathrm{Et}_{2} \mathrm{O}$ (48 mmol, 8.00 equiv.) was stirred at $90^{\circ} \mathrm{C}$ for 90 min under argon. The reaction mixture was poured into $10 \%$ aqueous $\mathrm{NaOAc}(100 \mathrm{~mL})$ and allowed to stir at room temperature for $24 \mathrm{~h}$, forming a brown precipitate. The precipitate was filtered and washed with $\mathrm{H}_{2} \mathrm{O}$ $(2 \times 20 \mathrm{~mL})$. The precipitate was resuspended with EtOAc, dried over $\mathrm{Na}_{2} \mathrm{SO}_{4}$ and finally concentrated in vacuo. The residue was purified by FC using a mixture of Petroleum Ether/EtOAc as eluent, to obtain the corresponding deoxybenzoin (3a-d) (Supplementary Material)

General procedure for the Vilsmeier-Haack reaction for the preparation of isoflavones (4a-d). In a two-neck round-bottom flask a solution of deoxybenzoin (3a-d) ( $3 \mathrm{mmol}, 1.00$ equiv.) in DMF ( $5 \mathrm{~mL}$ ) was cooled to $0{ }^{\circ} \mathrm{C}$ and $\mathrm{BF}_{3} \cdot \mathrm{Et}_{2} \mathrm{O}$ ( $9 \mathrm{mmol}$, 3.00 equiv.) was added dropwise under argon. In another flask, DMF $(8 \mathrm{~mL})$ was cooled to $0{ }^{\circ} \mathrm{C}$ and $\mathrm{PCl}_{5}$ (4.5 mmol, 1.50 equiv.) was added. The mixture was then allowed to stir at $55^{\circ} \mathrm{C}$ for $20 \mathrm{~min}$. The light yellow colored solution containing $N, N^{\prime}$-dimethyl (chloromethylene)ammonium chloride was then added to the above reaction mixture at $0^{\circ} \mathrm{C}$. The mixture was stirred at room temperature for $2 \mathrm{~h}$ under argon and then poured into $0.1 \mathrm{~N}$ methanolic $\mathrm{HCl}(70 \mathrm{~mL})$ and allowed to stir at $70^{\circ} \mathrm{C}$ for $2 \mathrm{~h}$. After removing the solvents in vacuo, $\mathrm{H}_{2} \mathrm{O}(50 \mathrm{~mL})$ and EtOAc $(50 \mathrm{~mL})$ were added and the aqueous phase was extracted with EtOAc $(3 \times 100 \mathrm{~mL})$. The combined organic layers were washed once with brine $(100 \mathrm{~mL})$, dried over $\mathrm{Na}_{2} \mathrm{SO}_{4}$, and finally concentrated under reduced pressure. The residue was purified by FC using Petroleum Ether/EtOAc as eluent, to give the corresponding isoflavone (4a-d) (Supplementary Material).

General procedure for the alkylation/benzylation reaction (5-19). To a solution of the isoflavone $(\mathbf{4 a - d})(0.18 \mathrm{mmol}, 1.00$ equiv.) in acetone ( $5 \mathrm{~mL}), \mathrm{K}_{2} \mathrm{CO}_{3}$ ( $1.8 \mathrm{mmol}, 10.00$ equiv.) was added. After stirring for $15 \mathrm{~min}$ the corresponding alkyl/benzyl bromide ( $0.9 \mathrm{mmol}, 5.00$ equiv.) was added drop wise to the mixture and stirred at $45^{\circ} \mathrm{C}$ overnight. After removing the acetone in vacuo, $\mathrm{H}_{2} \mathrm{O}$ $(10 \mathrm{~mL})$ and EtOAc $(20 \mathrm{~mL})$ were added and the aqueous phase was extracted with EtOAc $(3 \times 20 \mathrm{~mL})$. The combined organic layers were dried over $\mathrm{Na}_{2} \mathrm{SO}_{4}$, and finally concentrated under reduced pressure. The residue was purified by FC using Petroleum Ether/ EtOAc as eluent to give the corresponding substituted-isoflavone (5-19) (Supplementary Material).

\subsection{Molecular modeling}

Molecular modeling simulations were performed as reported previously against both targets. Briefly, molecular docking to Gli1ZF was carried out by GOLD docking program (version 5.0.1) [46,47] using the crystallographic structure of Gli1ZF in complex with DNA as rigid receptor (PDB 2GLI) [43]. Docking settings have been described previously [22]. Molecular docking to the Smo receptor was carried out by FRED docking program (version 3.0.1) using the crystallographic structure of Smo in complex with the natural product antagonist cyclopamine (PDB 4O9R). Docking settings have been described previously [17].

\subsection{Biology}

Cell cultures, transfection and treatments. Shh-Light II, MEFs WT, $\mathrm{SuFu}^{-1-}$ MEFs and $\mathrm{Smo}^{-1-}$ MEFs were cultured in DMEM plus $10 \%$ FBS, antibiotics and L-glutamine. Murine MBs were freshly isolated from Ptch ${ }^{ \pm}$mice (The Jackson Laboratory, Bar Harbor, ME, USA/ EMMA, Monterotondo, Italy) as previously described [48]. Cells were cultured in Neurobasal Media-A with B27 supplement minus vitamin A [49]. Mycoplasma contamination in cell cultures was routinely detected by using PCR detection kit (Applied Biological Materials, Richmond, BC, Canada). Transient transfections were performed using DreamFect ${ }^{\mathrm{TM}}$ Gold transfection reagent $(\mathrm{Oz}$ Biosciences SAS, Marseille, France). Cells were treated with SAG (200 nM, Alexis Biochemicals Farmingdale, NY, USA). Vismodegib was purchased from Selleckchem.com (Munich, Germany).

Hh-dependent luciferase reporter assay. The luciferase assay was performed in Shh-Light II cells, stably incorporating a Gliresponsive luciferase reporter and the pRL-TK Renilla (Normalization control), treated for $48 \mathrm{~h}$ with SAG ( $200 \mathrm{nM}$ ) and the studied compounds. Luciferase and Renilla activity were assayed with a dual-luciferase assay system according to the manufacturer's instruction (Biotium Inc., Hayward, CA, USA). Results are expressed as Luciferase/Renilla ratios and represent the mean \pm SD of three independent experiments, each performed in triplicate.

mRNA expression analysis. Total RNA was isolated with TRIzol (Thermo Fisher Scientific) and reverse-transcribed with SensiFAST cDNA Synthesis Kit (Bioline Reagents Limited, London, UK). Quantitative real-time PCR (Q-PCR) analysis of Gli1, Gli2 and HPRT mRNA expression was performed on each cDNA sample using the ViiA ${ }^{\mathrm{TM}} 7$ Real-Time PCR System employing Assay-on-Demand Reagents (Life Technologies, Foster City, CA, USA). A reaction mixture containing cDNA template, SensiFAST Probe Lo-ROX Kit (Bioline Reagents Limited) and primer probe mixture was amplified using FAST QPCR thermal cycler parameters. Each amplification reaction was performed in triplicate and the average of the three threshold cycles was used to calculate the amount of transcript in the sample (using SDS version 2.3 software). mRNA quantification was expressed, in arbitrary units, as the ratio of the sample quantity to the calibrator. All values were normalized with the endogenous control HPRT.

Statistical analysis. Statistical analysis was performed using the StatView 4.1 software (Abacus Concepts, Berkeley, CA, USA). Statistical tests were appropriately chosen for each experiment. For all other experiments, $P$-values were determined using Student's $t$-test and statistical significance was set at $P<0.05$. Results are expressed as mean \pm SD from an appropriate number of experiments (at least three biological replicates).

\section{Results and discussion}

\subsection{Computational design of isoflavones targeting Smo or Gli1}

In a previous study, a number of GlaB chemical derivatives (DBG1-5, Fig. 1) bearing modifications to the ring B have been synthesized and tested as Hh inhibitors [22], showing no effects. These data clearly highlighted the pharmacophoric relevance of the substitutions at the isoflavone's ring B in binding to Gli1 and preventing its interaction to DNA. Therefore, here we designed a smallsize focused library of isoflavones bearing different substituents in different positions of the ring B. Molecules were then tested in silico for the interaction with the heptahelical bundle of Smo or the DNA binding site of Gli1. To this aim, the computational protocols already established and validated in previous works were used $[17,18,22,23,50]$. Results unequivocally show that, for most of tested compounds, the $\mathrm{O}$-substitution at para position of ring $\mathrm{B}$ is 
preferred for the interaction with Smo, whereas the same substitution at meta position is preferred to interact with Gli1. This peculiar behavior could be explained by analyzing the shape of the binding sites on Smo or Gli1. Indeed, the canonical binding site of Smo is narrow and is elongated within the heptahelical bundle of the receptor with a linear geometry, while the binding site of Gli1 at the interface between zinc fingers (ZF) ZF4 and ZF5 is solvent exposed and slightly bended compared to the site in Smo.

Based on molecular modeling suggestions, we decided to synthesize the compounds listed in Table 1 (namely, the intermediate 4c, and the final compounds 5-19) to investigate their effects on the modulation of $\mathrm{Hh}$ signaling. To depict structural determinants responsible for specific binding to each target, the same substituents were introduced, where possible, at meta position of ring B to target preferentially Gli1, or at para position of ring B to target preferentially Smo.

\subsection{Chemistry}

Several synthetic procedures have been complied for the preparation of isoflavones [51]. Most of them have major drawbacks, including the use of special and expensive reagents in large excess, long reaction times, vigorous conditions and very low yields. We previously provided a synthetic route for the total synthesis of GlaB featuring six-step with an overall yield of 7\% [52], based on a palladium catalyzed cross coupling reaction of 3-iodochromone with the corresponding arylboronic acid. However, this approach is overall unfeasible for the synthesis of GlaB-ring B derivatives, due to the challenging mono-functionalization of the two hydroxylgroups in ring B. This prompted us to develop a mild and cost effective method, inspired by the so called deoxybenzoin route [53], which would allow the preparation of isoflavones bearing different substituents on meta and para positions of ring B. In this case, the isoflavone moiety was built in only two steps, involving first a Friedel-Crafts acylation and then a Vilsmeier-Haak reaction (Scheme 1). Suitably substituted phenyl acetic acids (2a-d) are fundamental to achieve the synthesis of free meta- or para-hydroxyl groups in ring $B$. The late stage functionalization of those accomplished the preparation of a small library of GlaB-ring B

Table 1

Chemical structure of isoflavone derivatives investigated in this work as Hh inhibitors.

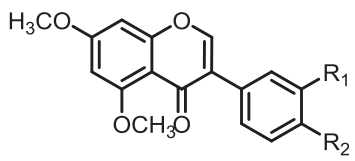

\begin{tabular}{|c|c|c|c|c|c|}
\hline Cmpd & $\mathrm{R}_{1}$ & $\mathrm{R}_{2}$ & Cmpd & $\mathrm{R}_{1}$ & $\mathrm{R}_{2}$ \\
\hline GlaB & -OPrenyl & -OPrenyl & 12 & $-\mathrm{Op}-\mathrm{BnCF}_{3}$ & $-\mathrm{OCH}_{3}$ \\
\hline $4 c$ & $-\mathrm{OH}$ & $-\mathrm{H}$ & 13 & $-\mathrm{OCH}_{3}$ & $-\mathrm{Op}-\mathrm{BnCF}_{3}$ \\
\hline 5 & -OPrenyl & $-\mathrm{OCH}_{3}$ & 14 & $-\mathrm{Op}-\mathrm{BnCF}_{3}$ & $-\mathrm{H}$ \\
\hline 6 & $-\mathrm{OCH}_{3}$ & -OPrenyl & 15 & $-\mathrm{OBn}$ & $-\mathrm{OBn}$ \\
\hline 7 & -OPrenyl & $-\mathrm{H}$ & 16 & $-\mathrm{Op}-\mathrm{BnCN}$ & $-\mathrm{OCH}_{3}$ \\
\hline 8 & $-\mathrm{OBn}$ & $-\mathrm{OCH}_{3}$ & 17 & $-\mathrm{Op}-\mathrm{BnCOOCH}_{3}$ & $-\mathrm{OCH}_{3}$ \\
\hline 9 & $-\mathrm{OCH}_{3}$ & $-\mathrm{OBn}$ & 18 & $-\mathrm{Op}-\mathrm{BnCOONH} \mathrm{H}_{2}$ & $-\mathrm{OCH}_{3}$ \\
\hline 10 & -OGeranyl & $-\mathrm{OCH}_{3}$ & 19 & $-\mathrm{Op}-\mathrm{BnNO}_{2}$ & $-\mathrm{OCH}_{3}$ \\
\hline 11 & $-\mathrm{OCH}_{3}$ & -OGeranyl & & & \\
\hline
\end{tabular}

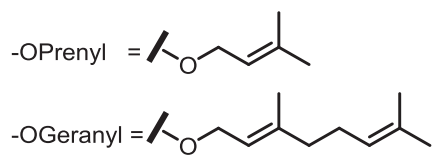

derivatives meta- or para-substituted (5-19) (Table 1 ), ready to be tested against the Hh pathway by means of functional assays, as described below.

\subsection{Hh inhibition by newly synthesized isoflavones}

The Hh inhibitory properties of synthesized compounds were investigated in a luciferase reporter assay, which is widely used for characterizing Hh antagonists. To this end, NIH3T3 Shh-Light II cells stably incorporating a Gli-responsive firefly luciferase reporter (Gli$\mathrm{RE})$ and the pRL-TK Renilla as normalization control, were treated with the synthetic Smo agonist SAG alone or in combination with the selected molecules, to evaluate their ability to suppress $\mathrm{Hh}$ signaling. Among the tested molecules with the presence of a substituent at meta position of the ring B, compounds 4c, 14, 16, 17, 18 and 19 showed mild activity at the maximum concentration of $30 \mu \mathrm{M} ; \mathbf{5}, \mathbf{8}, \mathbf{1 0}$, and 12 showed high activity with an $\mathrm{IC}_{50}$ ranging from 2 to $4 \mu \mathrm{M}$; 7 was inactive (Table 2 and Supplementary Material Figure S1A and Figure S2). Among molecules with the presence of a substituent at para position of the same ring, compounds $\mathbf{1 3}$ and $\mathbf{1 5}$ showed high activity as Hh inhibitors with an $\mathrm{IC}_{50}$ of $3.4 \mu \mathrm{M}$ and $0.29 \mu \mathrm{M}$, respectively; $\mathbf{6}$ and $\mathbf{9}$ showed mild activity, while $\mathbf{1 1}$ proved to be toxic (data not shown), as observed by a significant modulation of the internal control Renilla (Table 2 and Supplementary Material Figure S1B).

\subsection{Specificity of Smo and Gli antagonists}

To investigate the functional activity of the most active compounds as Gli1 or Smo modulators, we exploited the Gli1dependent luciferase reporter screening assay, in which mouse embryonic fibroblasts (MEFs) expressing ectopic Gli1 were treated with increasing concentrations of the selected small molecules. According to computational and experimental studies, compounds 5 and 12 proved to be the most powerful in inhibiting Gli1 activity, with an $\mathrm{IC}_{50}$ value between 5 and $11 \mu \mathrm{M}$ (Fig. 2 and Table 2). The FDA approved Smo antagonist Vismodegib (GDC-0449) was used as control to validate the assay method and, as expected, it showed no effect on Gli1 transcriptional activity (Supplementary Material Figure S2).

The ability of $\mathbf{5}$ and $\mathbf{1 2}$ to target Gli1 was confirmed in $\mathrm{Smo}^{-1-}$ MEFs transfected with ectopic Gli. As shown in Fig. 3, compounds 5 and 12 inhibited the luciferase activity driven by a Gli-responsive element (Fig. 3A), while compounds 13 and 15 did not (Fig. 3B). To further prove that compounds $\mathbf{5}$ and $\mathbf{1 2}$ operate downstream of Smo, we test such molecules in SuFu ${ }^{-1-}$ MEFs, in which the constitutive activation of the Hh pathway is due to the loss of the Gli negative regulator SuFu. In this cellular context, compounds $\mathbf{5}$ and 12 significantly reduced the constitutive endogenous expression of Gli1 and Gli2, the final effectors of the Hh signaling (Fig. 3C). As expected, compounds $\mathbf{1 3}$ and $\mathbf{1 5}$ fail in inhibiting Hh target gene expression because pathway activation occurs downstream of Smo receptor (Fig. 3D).

Overall, biological results are clearly in agreement with computational modeling predictions, showing that isoflavones bearing a substituent at para position of ring B target preferentially the upstream receptor Smo, whereas those bearing a substituent at meta position of ring B act mostly at the level of the downstream effectors Gli. The only exception to this rule is represented by compound 15, which bears a double bulky aryl substitution to the ring B and behaves as specific Smo antagonist. Notably, $\mathbf{1 5}$ is the most potent $\mathrm{Hh}$ inhibitor identified in this work, and was therefore investigated as Smo antagonist together with 13. The two most potent Gli antagonists, namely $\mathbf{5}$ and 12, were further investigated as well. 
<smiles>COc1cc(O)cc(OC)c1</smiles>
1<smiles>[R]c1ccc(CC(=O)O)cc1[R]</smiles>

2a, $\mathrm{R}_{1}=\mathrm{OH}, \mathrm{R}_{2}=\mathrm{OCH}_{3}$

2b, $\mathrm{R}_{1}=\mathrm{OCH}_{3}, \mathrm{R}_{2}=\mathrm{OH}$

2c, $\mathrm{R}_{1}=\mathrm{OH}, \mathrm{R}_{2} \mathrm{H}$

2d, $\mathrm{R}_{1}=\mathrm{OH}, \mathrm{R}_{2}=\mathrm{OH}$<smiles>[R]c1ccc(CC(=O)c2c(O)cc(OC)cc2OC)cc1[R]</smiles>

3a, $\mathrm{R}_{1}=\mathrm{OH}, \mathrm{R}_{2}=\mathrm{OCH}_{3}$

3b, $\mathrm{R}_{1}=\mathrm{OCH}_{3}, \mathrm{R}_{2}=\mathrm{OH}$

3c, $\mathrm{R}_{1}=\mathrm{OH}, \mathrm{R}_{2}=\mathrm{H}$

3d, $\mathrm{R}_{1}=\mathrm{OH}, \mathrm{R}_{2}=\mathrm{OH}$

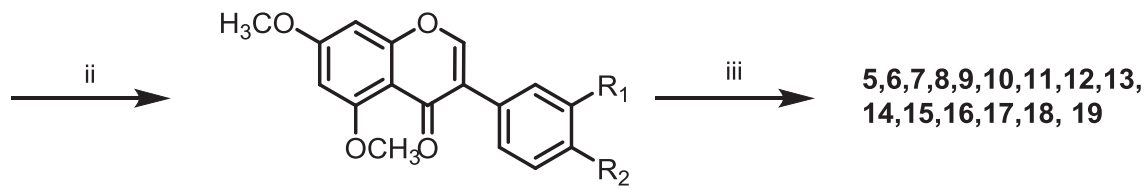

4a, $\mathrm{R}_{1}=\mathrm{OH}, \mathrm{R}_{2}=\mathrm{OCH}_{3}$

4b, $\mathrm{R}_{1}=\mathrm{OCH}_{3}, \mathrm{R}_{2}=\mathrm{OH}$

4c, $\mathrm{R}_{1}=\mathrm{OH}, \mathrm{R}_{2}=\mathrm{H}$

4d, $\mathrm{R}_{1}=\mathrm{OH}, \mathrm{R}_{2}=\mathrm{OH}$

Scheme 1. Deoxybenzoin approach for the synthesis of GlaB-ring B derivatives: i) $\mathrm{BF}_{3} \cdot \mathrm{OEt}_{2}, 90{ }^{\circ} \mathrm{C}, 90$ min $50-60 \%$; ii) $\mathrm{BF}_{3} \cdot \mathrm{OEt}_{2}$, (chloromethylene)dimethyliminium chloride, $\mathrm{DMF}$, rt, $2 \mathrm{~h} 28-32 \%$; iii) alkyl- or benzyl-bromide, $\mathrm{K}_{2} \mathrm{CO}_{3}$, acetone, $45^{\circ} \mathrm{C}, 17 \mathrm{~h}, 88-95 \%$.

Table 2

$\mathrm{IC}_{50}$ values for selected compounds in the Shh-Light II cells and in MEFs assays.

\begin{tabular}{lll}
\hline & Substitution at meta position & \\
\cline { 2 - 3 } & Shh-Light II IC $50(\mu \mathrm{M})$ & ${\text { MEFs } \mathrm{IC}_{50}(\mu \mathrm{M})}$ \\
\hline $\mathbf{5}$ & $2.87 \pm 0.33$ & $5.695 \pm 0.84$ \\
$\mathbf{8}$ & $3.719 \pm 0.88$ & $17.12 \pm 0.87$ \\
$\mathbf{1 0}$ & $3.61 \pm 0.31$ & $21.22 \pm 1.21$ \\
$\mathbf{1 2}$ & $2.58 \pm 0.12$ & $11.50 \pm 0.85$ \\
$\mathbf{1 6}$ & $16 \pm 1.1$ & nd \\
$\mathbf{1 7}$ & $>30$ & nd \\
$\mathbf{1 8}$ & $>30$ & nd \\
$\mathbf{1 9}$ & $>30$ & nd \\
$\mathbf{4 c}$ & $>30$ & nd \\
$\mathbf{7}$ & $>30$ & $>20$ \\
$\mathbf{1 4}$ & $10.47 \pm 0.73$ & $26.73 \pm 1.7$ \\
\hline & Substitution at para position & \\
\hline & Shh-Light II IC $50(\mu \mathbf{M})$ & MEFs IC \\
& $6.97 \pm 0.67$ & $10.7 \pm 1.01$ \\
\hline $\mathbf{6}$ & $6.921 \pm 0.76$ & $39.2 \pm 2.03$ \\
$\mathbf{9}$ & nd & nd \\
$\mathbf{1 1}$ & $3.477 \pm 0.66$ & $55.29 \pm 2.57$ \\
$\mathbf{1 3}$ & $0.29 \pm 0.12$ & $57.74 \pm 3.98$ \\
$\mathbf{1 5}$ & &
\end{tabular}

nd: not determined.

\subsection{Predicted binding mode of the most powerful Hh inhibitors}

The possible binding mode of the most interesting Hh inhibitors towards Smo or Gli1 crystallographic structure was investigated by molecular modeling simulations. It is worth noting that previous studies performed by our research group highlighted the reliability of computational tools in predicting the binding mode of Gli1 antagonists (i.e. the docking-based binding mode of GlaB was supported by multiple experimental evidences) [22], and Smo antagonists (the docking pose of Vismodegib was subsequently confirmed by X-ray crystallography studies) [44,50]. Therefore, these established computational protocols were used herein to dock 5 and 12 towards Gli1 zinc-finger (ZF) domain (Gli1ZF) and to dock 13 and 15 within the heptahelical bundle of Smo. Two different docking programs were used (i.e. GOLD to dock against Gli1, and FRED to dock against Smo) according to the different
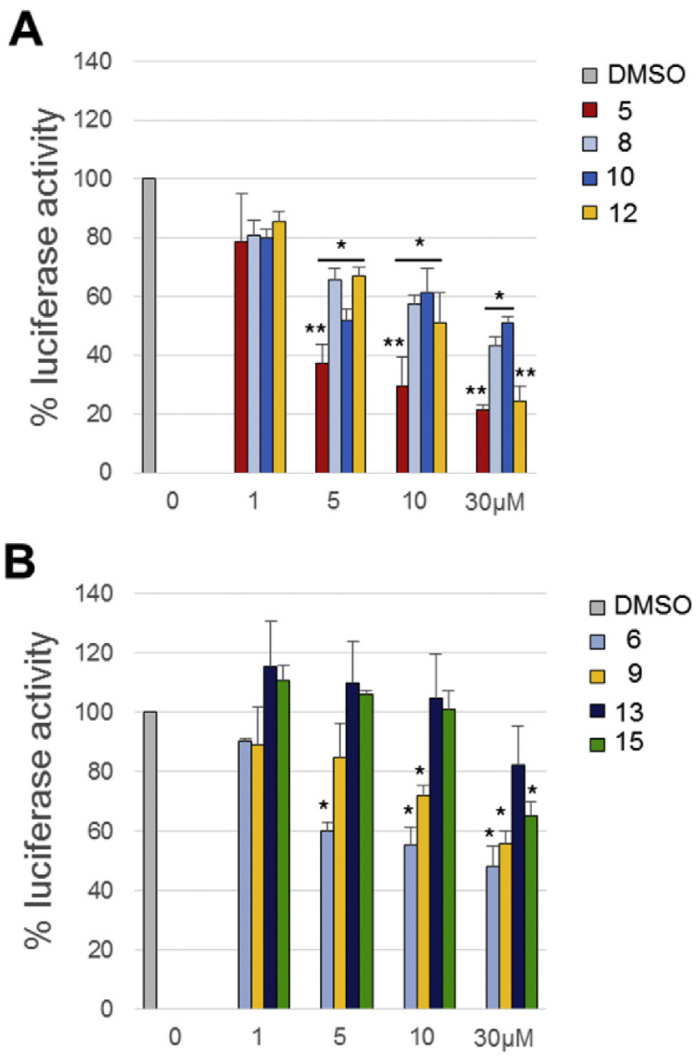

Fig. 2. Specificity of Smo and Gli antagonists. Inhibition of Gli1-induced transcription was assessed in MEFs transfected with 12XGliBS-Luc and pRL-TK Renilla (normalization control) plus control (empty) or Gli1 vector and treated with increasing concentrations of selected compounds with a substituent at meta (A) or at para (B) position of ring B. Treatment time was $24 \mathrm{~h}$; control cells were treated with DMSO only. In all experiments data show the mean \pm SD of three independent experiments: $\left({ }^{*}\right) \mathrm{P}<0.05$ vs CTR (DMSO); (**) P $<0.01$ vs CTR (DMSO).

shape and features of the binding sites, as well as to prior benchmarking studies mentioned above. 
A

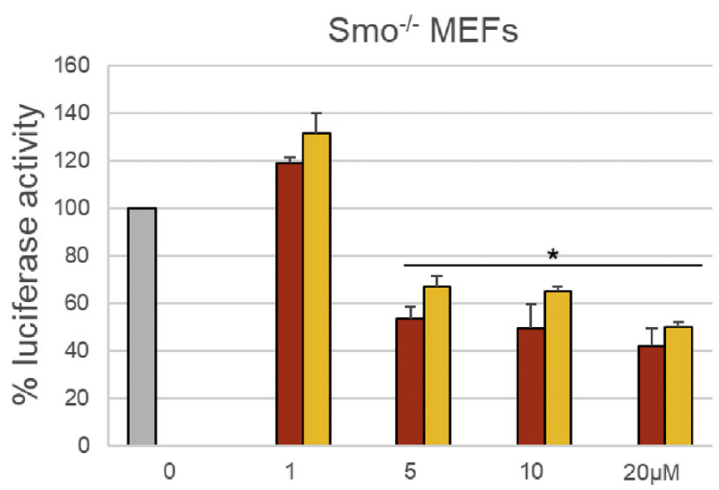

B

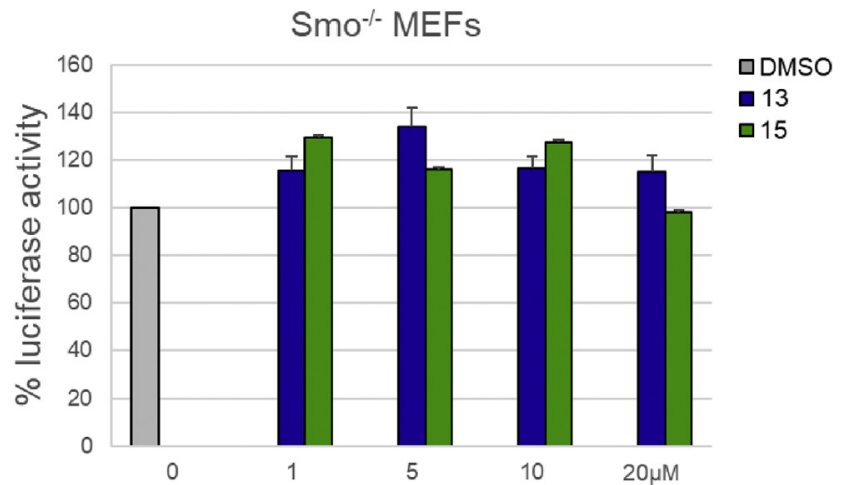

C 口DMSO $\square 5$ $\square 12$

D
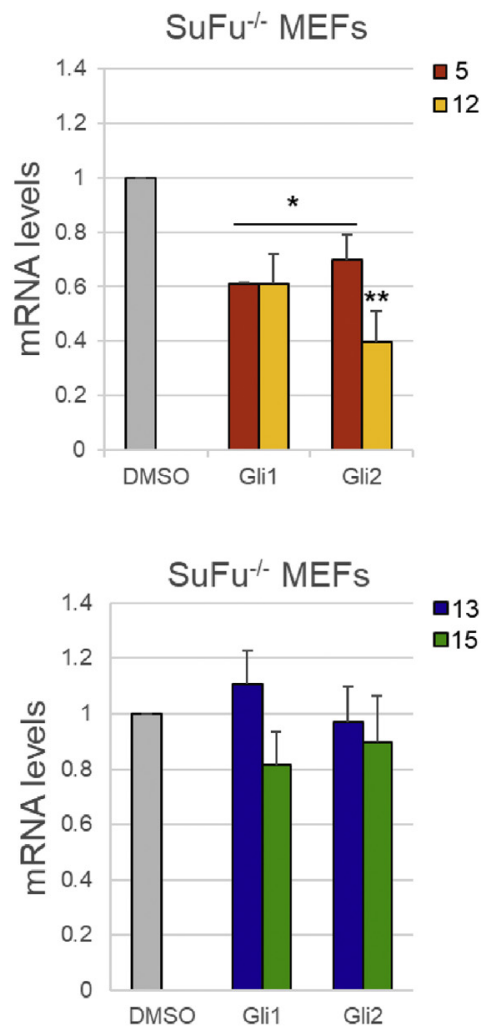

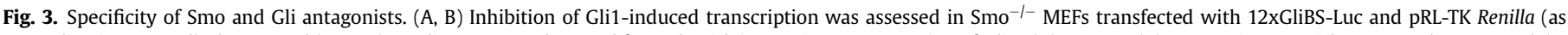

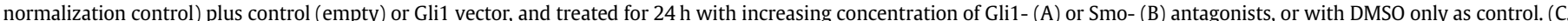

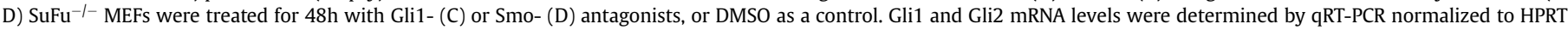
expression. In all experiments data show the mean \pm SD of three independent experiments: $\left(^{*}\right) \mathrm{P}<0.05 ;\left({ }^{* *}\right) \mathrm{P}<0.01 \mathrm{vs} C \mathrm{CTR}(\mathrm{DMSO})$.

Molecular docking towards Gli1ZF clearly showed that $\mathbf{5}$ and $\mathbf{1 2}$ share a highly comparable binding mode each other, with the isoflavone core occupying a surface region at the interface between ZF4 and ZF5 (Fig. 4). In particular, the core establishes H-bond interactions with Lys350, which has been previously highlighted by mutagenesis studies to be a key determinant for Gli1 transcriptional activity [22], with Thr355, Lys360, and the Zn-binding His351, (Fig. 4). The isoflavone ring B is docked in a pose that hides the nuclear localization system (NLS) in correspondance of residue Thr374 to the solvent area [54]. The isoprenyl group linked to the ring B in $\mathbf{5}$ is docked in a groove near Ser357 and Asn358 (Fig. 4A), while the aromatic moiety of $\mathbf{1 2}$ is projected towards the
ZF5 where it interacts with the side chain of Tyr373 by means of a Tshaped $\pi-\pi$ stacking interaction (Fig. 4B). These binding modes are highly comparable to that of GlaB even though the isoflavone core is oriented in a slightly different manner [22], and account for a direct competition between these Gli1 antagonists and DNA.

In the case of Smo, both $\mathbf{1 3}$ and $\mathbf{1 5}$ are able to fit the narrow lipophilic site located within the heptahelical bundle of the receptor, and to interact with key residues already highlighted in structural and computational studies. Different than Gli1, the isoflavone core of the Smo antagonists binds in two different conformations, which are most likely biased by the presence of two bulky aryl substituents on the ring $\mathrm{B}$ of $\mathbf{1 5}$ compared to the single
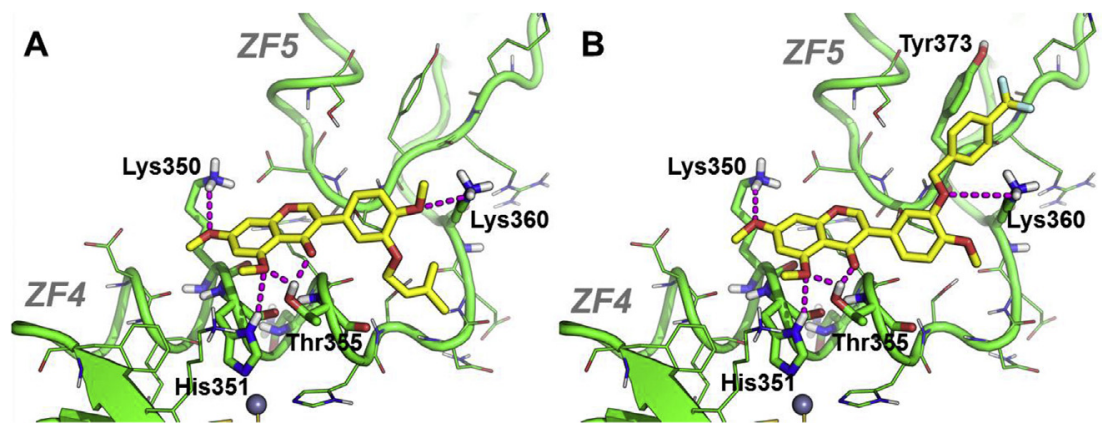

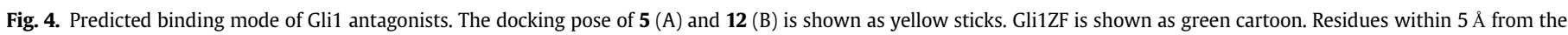

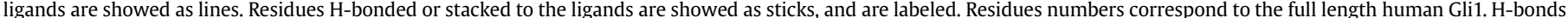

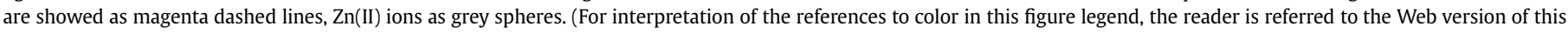
article.) 
substituent at para position of ring B of $\mathbf{1 3}$ (Fig. 5).

The isoflavone core of $\mathbf{1 3}$ binds deeply in a region of Smo that is occupied by multiple antagonists, as elucidated by X-ray crystallography [17,28,42,44,45], and establishes H-bond with Arg400 and Tyr394 (Fig. 5A), this latter being $\pi-\pi$ stacked to the compound. Another $\pi-\pi$ stacking interaction is established by 13 with the side chain of Phe484. As already observed in other Smo antagonists, the trifluoromethyl group is docked near the entrance of the binding site in correspondence of the extracellular portion of Smo, whereas lipophilic moieties are preferentially docked within the intramembrane region of the receptor $[42,55]$. This pharmacophoric preference might also explain why, in the case of $\mathbf{1 5}$, the isoflavone core binds with opposite orientation near the extracellular region of Smo. Indeed, ring B is substituted with two hydrophobic benzyloxy groups that are projected deeply in the heptahelical bundle of Smo in close proximity to non-polar residues such as Phe222, Met230, Trp281, Phe391, His470, Leu515, and Leu522. Among them, His470 establishes a T-shaped $\pi-\pi$ interaction with the benzyloxy group substituted at para position of ring B (Fig. 5B). The compound also establishes H-bond interactions with Asn219, Gln477, and Tyr394, this latter becoming $\pi-\pi$ stacked to the ring $\mathrm{B}$.

Overall, the binding modes predicted by molecular modeling towards Gli1 and Smo are supportive of the interaction of these isoflavones with their respective targets, as well as of the specific mechanism of Hh inhibition.

\subsection{Synergistic combination of isoflavone Smo and Gli antagonists}

Hh pathway alteration through a ligand-dependent or independent mechanism is a key driver in tumorigenesis. For this reason, the development of $\mathrm{Hh}$ inhibitors is eliciting great interest in drug discovery. Events as drug resistance or the presence of by stander co-regulatory mechanism of the Hh pathway, highlight the necessity to discover new effective Hh inhibitors for cancer therapy.

To this end, the synergistic effect elicited by two isoflavones targeting specifically Smo or Gli1 was tested. The ability to inhibit Hh-dependent tumor growth was analyzed in primary MB cells that were freshly isolated from Ptch ${ }^{ \pm}$mice tumors and tested in short-term cultures to keep Hh sensitivity in vitro [4]. As shown in Table 3 (Supplementary Material Figure S4), single compound
Table 3

Percentage of growth inhibition of primary MB cells freshly isolated from Ptch ${ }^{ \pm}$ mice, after $72 \mathrm{~h}$ of treatment with the selected compounds.

\begin{tabular}{llllll}
\hline$[\mu \mathrm{M}]$ & $\mathrm{GlaB}$ & 5 & 12 & 13 & 15 \\
\hline 0.125 & $28.6 \pm 2.7$ & $5.9 \pm 3$ & $37.7 \pm 3.1$ & $20.8 \pm 5.3$ & $33.3 \pm 3.8$ \\
0.25 & $42.4 \pm 3.1$ & $26.3 \pm 4$ & $40.6 \pm 2.3$ & $23.5 \pm 3.1$ & $44.2 \pm 4.9$ \\
0.5 & $46.6 \pm 3.4$ & $29.2 \pm 3.6$ & $44.52 \pm 3.6$ & $32.5 \pm 1.3$ & $51.4 \pm 5.1$ \\
1 & $55.9 \pm 4$ & $35.6 \pm 2.1$ & $50.9 \pm 4.8$ & $51.8 \pm 3.5$ & $61.2 \pm 4.8$ \\
5 & $65.1 \pm 5.3$ & $55.4 \pm 5$ & $54 \pm 5$ & $54.2 \pm 4.4$ & $66.6 \pm 4.1$ \\
\hline
\end{tabular}

treatments inhibited the cell growth with comparable potency to the reference isoflavone Hh inhibitor GlaB.

In contrast, the binary combination between a Smo (13 or 15) and a Gli1 (5 or $\mathbf{1 2}$ or GlaB) antagonist impaired cell proliferation at noticeably lower concentrations (Table 4, and Supplementary Material Figure S5). Indeed, we observed a similar inhibition on cell growth in primary MB cells treated with GlaB alone at the concentration of $0.5 \mu \mathrm{M}$ ( $46 \%$ growth inhibition, Table 3 ), compared to binary combination of compounds $\mathbf{1 2}$ and $\mathbf{1 3}$ at the final concentration of $0.125 \mu \mathrm{M}$ (Table 4).

The binary combination of GlaB with compound 13 or compound 15 at the concentration of $0.25 \mu \mathrm{M}$ showed $53 \%$ and $63.4 \%$ Hh-dependent tumor growth inhibition, respectively. The most powerful effect was achieved by the combined treatment with GlaB and compound 15 at the concentration of $0.5 \mu \mathrm{M}$, which displayed a $70 \%$ cell growth inhibition (Table 4 and Supplementary Material Figure S5).

Table 4

Percentage of growth inhibition in primary MB cells freshly isolated from Ptch ${ }^{ \pm}$ mice, after $72 \mathrm{~h}$ of treatment with the binary combination of a Gli1-and a Smoantagonist.

\begin{tabular}{lllllll}
\hline$[\mu \mathrm{M}]$ & $12+13$ & $12+15$ & $5+13$ & $5+15$ & GlaB +13 & GlaB +15 \\
\hline 0.125 & $44.2 \pm 2.7$ & $35.5 \pm 5$ & $31.8 \pm 2.7$ & $32.0 \pm 4.6$ & $33.5 \pm 1.1$ & $38.3 \pm 4.7$ \\
0.25 & $50.1 \pm 2.9$ & $50 \pm 3.7$ & $33 \pm 2$ & $34 \pm 2.1$ & $53.1 \pm 2.5$ & $63.4 \pm 3.1$ \\
0.5 & $53.5 \pm 3.9$ & $55.2 \pm 4.6$ & $35 \pm 3.3$ & $40 \pm 3.6$ & $60.1 \pm 1.6$ & $70 \pm 4.2$ \\
1 & $61.9 \pm 3.4$ & $67.9 \pm 3.8$ & $45.7 \pm 3$ & $51.9 \pm 2.7$ & nd & nd \\
2 & $58.6 \pm 4$ & $68.2 \pm 1.3$ & $47.1 \pm 1.5$ & $60.4 \pm 1.5$ & nd & nd \\
\hline
\end{tabular}

nd: not determined.

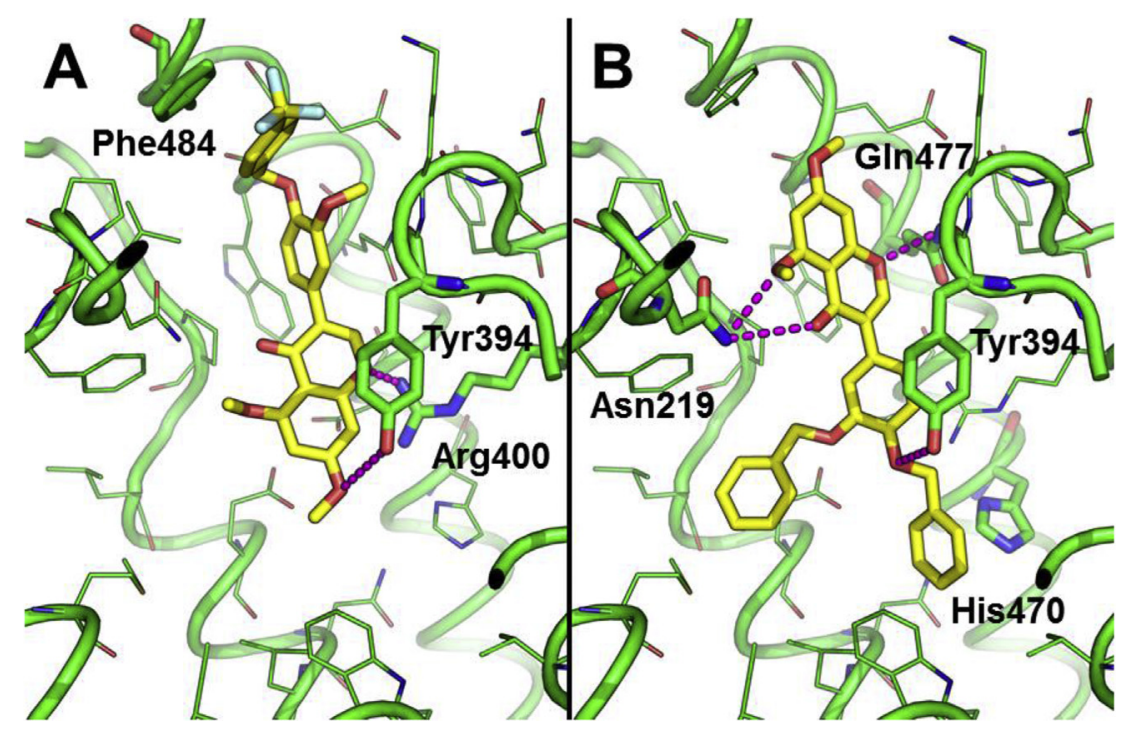

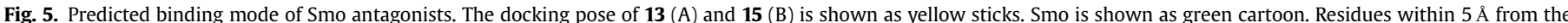

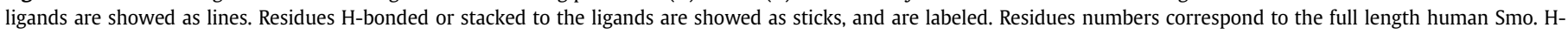
bonds are showed as magenta dashed lines. (For interpretation of the references to color in this figure legend, the reader is referred to the Web version of this article.) 
Overall, our data represent a proof-of-concept that targeting the Hh pathway at both upstream and downstream levels stands by as a new and more effective strategy to repress the Hh-dependent tumor growth.

\section{Conclusion}

Abnormal Hh activation is a hallmark of many cancers, and several germline or somatic mutations in Hh pathway components, have been documented in BCC, MB, rhabdomyosarcoma (RMS), meningioma, and many other tumors. Pharmacological Hh inhibition has emerged as a valuable anticancer strategy as underlined by Vismodegib and Sonidegib, two Smo antagonists approved by the FDA in 2012 and 2015, respectively, for the treatment of metastatic or locally-advanced BCC [19]. However, drug-resistant mutations occurring at the Smo receptor as a consequence of pharmacological pressure, coupled with $\mathrm{Hh}$ activation downstream or independently of Smo, have raised the need to identify novel strategy to inhibit Hh signaling [12,29]. In this regard, one of the most promising Hh target is the final and most powerful effector Gli1, whose druggability has been assessed by means of the isoflavone GlaB [22], and the synthetic molecule GANT-61, although this latter suffers from chemical instability as substantiated recently $[23,56]$.

Since the isoflavone emerged as privileged scaffold in Hh inhibition, based on molecular modeling predictions and prior studies [17,22], here we designed a number of isoflavones able to interact preferentially with the Smo receptor or the Gli protein. Molecules were synthesized by means of a novel synthetic pathway, and were tested in vitro. Experimental results confirmed molecular modeling predictions, showing that isoflavones substituted in meta to the ring B bind preferentially to Gli1ZF domain, whereas isoflavones substituted in para position bind preferentially the Smo receptor. Notably, molecules were also able to inhibit Hh-dependent tumor growth in primary MB cells at sub-micromolar concentration.

Compared to GlaB, the combined administration of a Smo and a Gli antagonist provided similar Hh inhibition effects with individual doses of compounds $\mathbf{1 2}$ and $\mathbf{1 3}$ decreased by four times ( 0.5 vs $0.125 \mu \mathrm{M}$ ) even though the strongest Hh inhibition was achieved by the combination of GlaB and $\mathbf{1 5}$ at the concentration of $0.5 \mu \mathrm{M}(70 \%$ inhibition vs $46 \%$ inhibition by GlaB alone at $0.5 \mu \mathrm{M}$ ).

As highlighted by a recent survey on active anticancer clinical trials (data not shown) and literature reports [57-59], combination of two (or more) drugs with documented high single-agent response rates and distinct mechanisms of action is expected to be more effective than administration of either agent alone. Target therapy based on binary drugs combinations became a paradigm particularly in anticancer drug development, not only to increase efficacy, but also to decrease toxicity of individual anticancer agents. Despite Hh inhibitors are combined in clinical trials with conventional anticancer agents, our data highlighted that targeting specifically Hh pathway at both upstream and downstream levels through the combination of a Smo with a Gli antagonist efficiently enhance $\mathrm{Hh}$ inhibition at lower individual compounds doses. Even though additional studies are needed to evaluate the ADME profile of these compounds, particularly with respect to possible drugdrug interactions, we expect that our study might trigger additional investigations on clinically relevant $\mathrm{Hh}$ inhibitors, and encourage the treatment of $\mathrm{Hh}$-dependent tumors with combination therapy.

\section{Acknowledgment}

We thank R. Toftgard for SuFu ${ }^{-1-}$ MEF and Smo ${ }^{-1-}$ MEFs. This work was supported by Associazione Italiana Ricerca Cancro (AIRC) Grant \#IG20801, Ministry of University and Research (PRIN 2012-
2013 (2012C5YJSK002), Pasteur Institute/Cenci Bolognetti Foundation Istituto Italiano di Tecnologia (IIT) and Progetti di Ricerca di Università Sapienza di Roma. The authors would like to acknowledge networking contribution by the COST Action CM1407 "Challenging organic syntheses inspired by nature - from natural products chemistry to drug discovery".

\section{Appendix A. Supplementary data}

Supplementary data related to this article can be found at https://doi.org/10.1016/j.ejmech.2018.07.017.

\section{References}

[1] J. Briscoe, P.P. Therond, The mechanisms of Hedgehog signalling and its roles in development and disease, Nat. Rev. Mol. Cell Biol. 14 (2013) 416-429.

[2] D.J. Robbins, D.L. Fei, N.A. Riobo, The Hedgehog signal transduction network, Sci. Signal. 5 (2012) re6.

[3] A. Ruiz i Altaba, P. Sanchez, N. Dahmane, Gli and hedgehog in cancer: tumours, embryos and stem cells, Nat. Rev. Canc. 2 (2002) 361-372.

[4] L.V. Goodrich, L. Milenkovic, K.M. Higgins, M.P. Scott, Altered neural cell fates and medulloblastoma in mouse patched mutants, Science 277 (1997) 1109-1113.

[5] D. Amakye, Z. Jagani, M. Dorsch, Unraveling the therapeutic potential of the Hedgehog pathway in cancer, Nat. Med. 19 (2013) 1410-1422.

[6] M.R. Gailani, M. Stahle-Backdahl, D.J. Leffell, M. Glynn, P.G. Zaphiropoulos, C. Pressman, A.B. Unden, M. Dean, D.E. Brash, A.E. Bale, R. Toftgard, The role of the human homologue of Drosophila patched in sporadic basal cell carcinomas, Nat. Genet. 14 (1996) 78-81.

[7] Y.H. Bian, S.H. Huang, L. Yang, X.L. Ma, J.W. Xie, H.W. Zhang, Sonic hedgehogGli1 pathway in colorectal adenocarcinomas, World J. Gastroenterol. 13 (2007) 1659-1665.

[8] A.N. Gerber, C.W. Wilson, Y.J. Li, P.T. Chuang, The hedgehog regulated oncogenes Gli1 and Gli2 block myoblast differentiation by inhibiting MyoDmediated transcriptional activation, Oncogene 26 (2007) 1122-1136.

[9] P. Sanchez, A.M. Hernandez, B. Stecca, A.J. Kahler, A.M. DeGueme, A. Barrett, M. Beyna, M.W. Datta, S. Datta, A. Ruiz i Altaba, Inhibition of prostate cancer proliferation by interference with SONIC HEDGEHOG-GLI1 signaling, Proc. Natl. Acad. Sci. U.S.A. 101 (2004) 12561-12566.

[10] P. Sanchez, V. Clement, A. Ruiz i Altaba, Therapeutic targeting of the Hedgehog-GLI pathway in prostate cancer, Canc. Res. 65 (2005) 2990-2992.

[11] E. Petricci, F. Manetti, Targeting the hedgehog signaling pathway with small molecules from natural sources, Curr. Med. Chem. 22 (2015) 4058-4090.

[12] P. Infante, R. Alfonsi, B. Botta, M. Mori, L. Di Marcotullio, Targeting GLI factors to inhibit the Hedgehog pathway, Trends Pharmacol. Sci. 36 (2015) 547-558.

[13] V. Iovine, M. Mori, A. Calcaterra, S. Berardozzi, B. Botta, One hundred faces of cyclopamine, Curr. Pharmaceut. Des. 22 (2016) 1658-1681.

[14] M. Xin, X. Ji, L.K. De La Cruz, S. Thareja, B. Wang, Strategies to target the Hedgehog signaling pathway for cancer therapy, Med. Res. Rev. 22 (2018) 870-913.

[15] X. Dong, C. Wang, Z. Chen, W. Zhao, Overcoming the resistance mechanisms of Smoothened inhibitors, Drug Discov. Today 23 (2018) 704-710.

[16] M. Ruat, L. Hoch, H. Faure, D. Rognan, Targeting of Smoothened for therapeutic gain, Trends Pharmacol. Sci. 35 (2014) 237-246.

[17] P. Infante, R. Alfonsi, C. Ingallina, D. Quaglio, F. Ghirga, I. D'Acquarica, F. Bernardi, L. Di Magno, G. Canettieri, I. Screpanti, A. Gulino, B. Botta, M. Mori, L. Di Marcotullio, Inhibition of Hedgehog-dependent tumors and cancer stem cells by a newly identified naturally occurring chemotype, Cell Death Dis. 7 (2016), e2376.

[18] R. Alfonsi, B. Botta, S. Cacchi, L. Di Marcotullio, G. Fabrizi, R. Faedda, A. Goggiamani, A. Iazzetti, M. Mori, Design, palladium-catalyzed synthesis, and biological investigation of 2-substituted 3-Aroylquinolin-4(1H)-ones as inhibitors of the hedgehog signaling pathway, J. Med. Chem. 60 (2017) $1469-1477$.

[19] A. Dlugosz, S. Agrawal, P. Kirkpatrick, Vismodegib, Nat. Rev. Drug Discov. 11 (2012) 437-438.

[20] E. De Smaele, E. Ferretti, A. Gulino, Vismodegib, a small-molecule inhibitor of the hedgehog pathway for the treatment of advanced cancers, Curr. Opin. Invest. Drugs 11 (2010) 707-718.

[21] C. Mas, A. Ruiz i Altaba, Small molecule modulation of HH-GLI signaling: current leads, trials and tribulations, Biochem. Pharmacol. 80 (2010) 712-723.

[22] P. Infante, M. Mori, R. Alfonsi, F. Ghirga, F. Aiello, S. Toscano, C. Ingallina, M. Siler, D. Cucchi, A. Po, E. Miele, D. D'Amico, G. Canettieri, E. De Smaele, E. Ferretti, I. Screpanti, G. Uccello Barretta, M. Botta, B. Botta, A. Gulino, L. Di Marcotullio, Gli1/DNA interaction is a druggable target for Hedgehogdependent tumors, EMBO J. 34 (2015) 200-217.

[23] A. Calcaterra, V. Iovine, B. Botta, D. Quaglio, I. D'Acquarica, A. Ciogli, A. Iazzetti, R. Alfonsi, L. Lospinoso Severini, P. Infante, L. Di Marcotullio, M. Mori, F. Ghirga, Chemical, computational and functional insights into the chemical stability of the Hedgehog pathway inhibitor GANT61, J. Enzym. Inhib. Med. 
Chem. 33 (2018) 349-358.

[24] G. Liu, W. Huang, J. Wang, X. Liu, J. Yang, Y. Zhang, Y. Geng, W. Tan, A. Zhang, Discovery of novel macrocyclic hedgehog pathway inhibitors acting by suppressing the gli-mediated transcription, J. Med. Chem. 60 (2017) 8218-8245.

[25] D. Casey, S. Demko, S. Shord, H. Zhao, H. Chen, K. He, A. Putman, W. Helms P. Keegan, R. Pazdur, FDA approval summary: Sonidegib for locally advanced basal cell carcinoma, Clin. Canc. Res. 23 (2017) 2377-2381.

[26] S.X. Atwood, K.Y. Sarin, R.J. Whitson, J.R. Li, G. Kim, M. Rezaee, M.S. Ally, J. Kim, C. Yao, A.L. Chang, A.E. Oro, J.Y. Tang, Smoothened variants explain the majority of drug resistance in Basal cell carcinoma, Canc. Cell 27 (2015) 342-353.

[27] H.J. Sharpe, G. Pau, G.J. Dijkgraaf, N. Basset-Seguin, Z. Modrusan, T. Januario, V. Tsui, A.B. Durham, A.A. Dlugosz, P.M. Haverty, R. Bourgon, J.Y. Tang, K.Y. Sarin, L. Dirix, D.C. Fisher, C.M. Rudin, H. Sofen, M.R. Migden, R.L. Yauch, F.J. de Sauvage, Genomic analysis of smoothened inhibitor resistance in basal cell carcinoma, Canc. Cell 27 (2015) 327-341.

[28] C. Wang, H. Wu, T. Evron, E. Vardy, G.W. Han, X.P. Huang, S.J. Hufeisen, T.J. Mangano, D.J. Urban, V. Katritch, V. Cherezov, M.G. Caron, B.L. Roth, R.C. Stevens, Structural basis for Smoothened receptor modulation and chemoresistance to anticancer drugs, Nat. Commun. 5 (2014) 4355.

[29] R.L. Yauch, G.J. Dijkgraaf, B. Alicke, T. Januario, C.P. Ahn, T. Holcomb, K. Pujara, J. Stinson, C.A. Callahan, T. Tang, J.F. Bazan, Z. Kan, S. Seshagiri, C.L. Hann, S.E. Gould, J.A. Low, C.M. Rudin, F.J. de Sauvage, Smoothened mutation confers resistance to a Hedgehog pathway inhibitor in medulloblastoma, Science 326 (2009) 572-574.

[30] E.M. Beauchamp, L. Ringer, G. Bulut, K.P. Sajwan, M.D. Hall, Y.C. Lee, D. Peaceman, M. Ozdemirli, O. Rodriguez, T.J. Macdonald, C. Albanese, J.A. Toretsky, A. Uren, Arsenic trioxide inhibits human cancer cell growth and tumor development in mice by blocking Hedgehog/GLI pathway, J. Clin. Invest. 121 (2011) 148-160.

[31] C. Bao, P. Kramata, H.J. Lee, N. Suh, Regulation of hedgehog signaling in cancer by natural and dietary compounds, Mol. Nutr. Food Res. 62 (2018).

[32] A.L. Harvey, R. Edrada-Ebel, R.J. Quinn, The re-emergence of natural products for drug discovery in the genomics era, Nat. Rev. Drug Discov. 14 (2015) $111-129$.

[33] J.P. Incardona, W. Gaffield, R.P. Kapur, H. Roelink, The teratogenic Veratrum alkaloid cyclopamine inhibits sonic hedgehog signal transduction, Development 125 (1998) 3553-3562.

[34] K. Zaheer, M. Humayoun Akhtar, An updated review of dietary isoflavones: nutrition, processing, bioavailability and impacts on human health, Crit. Rev. Food Sci. Nutr. 57 (2017) 1280-1293.

[35] H. Hussain, I.R. Green, A patent review of the therapeutic potential of isoflavones (2012-2016), Expert Opin. Ther. Pat. 27 (2017) 1135-1146.

[36] K.P. Ko, Isoflavones: chemistry, analysis, functions and effects on health and cancer, Asian Pac. J. Cancer Prev. APJCP 15 (2014) 7001-7010.

[37] A. Slusarz, N.S. Shenouda, M.S. Sakla, S.K. Drenkhahn, A.S. Narula, R.S. MacDonald, C.L. Besch-Williford, D.B. Lubahn, Common botanical compounds inhibit the hedgehog signaling pathway in prostate cancer, Canc. Res. 70 (2010) 3382-3390.

[38] L. Zhang, L. Li, M. Jiao, D. Wu, K. Wu, X. Li, G. Zhu, L. Yang, X. Wang, J.T. Hsieh, D. He, Genistein inhibits the stemness properties of prostate cancer cells through targeting Hedgehog-Gli1 pathway, Canc. Lett. 323 (2012) 48-57.

[39] D. Yu, H.S. Shin, Y.S. Lee, D. Lee, S. Kim, Y.C. Lee, Genistein attenuates cancer stem cell characteristics in gastric cancer through the downregulation of Gli1, Oncol. Rep. 31 (2014) 673-678.

[40] P. Fan, S. Fan, H. Wang, J. Mao, Y. Shi, M.M. Ibrahim, W. Ma, X. Yu, Z. Hou, B. Wang, L. Li, Genistein decreases the breast cancer stem-like cell population through Hedgehog pathway, Stem Cell Res. Ther. 4 (2013) 146

[41] C. Bao, H. Namgung, J. Lee, H.C. Park, J. Ko, H. Moon, H.W. Ko, H.J. Lee, Daidzein suppresses tumor necrosis factor-alpha induced migration and invasion by inhibiting hedgehog/Gli1 signaling in human breast cancer cells, J. Agric. Food Chem. 62 (2014) 3759-3767.

[42] C. Wang, H. Wu, V. Katritch, G.W. Han, X.P. Huang, W. Liu, F.Y. Siu, B.L. Roth,
V. Cherezov, R.C. Stevens, Structure of the human smoothened receptor bound to an antitumour agent, Nature 497 (2013) 338-343.

[43] N.P. Pavletich, C.O. Pabo, Crystal structure of a five-finger GLI-DNA complex: new perspectives on zinc fingers, Science 261 (1993) 1701-1707.

44] E.F.X. Byrne, R. Sircar, P.S. Miller, G. Hedger, G. Luchetti, S. Nachtergaele M.D. Tully, L Mydock-McGrane, D.F. Covey, R.P. Rambo, M.S.P. Sansom, S. Newstead, R. Rohatgi, C. Siebold, Structural basis of Smoothened regulation by its extracellular domains, Nature 535 (2016) 517-522.

[45] U. Weierstall, D. James, C. Wang, T.A. White, D. Wang, W. Liu, J.C. Spence, R. Bruce Doak, G. Nelson, P. Fromme, R. Fromme, I. Grotjohann, C. Kupitz, N.A. Zatsepin, H. Liu, S. Basu, D. Wacker, G.W. Han, V. Katritch, S. Boutet, M. Messerschmidt, G.J. Williams, J.E. Koglin, M. Marvin Seibert, M. Klinker, C. Gati, R.L. Shoeman, A. Barty, H.N. Chapman, R.A. Kirian, K.R. Beyerlein, R.C. Stevens, D. Li, S.T. Shah, N. Howe, M. Caffrey, V. Cherezov, Lipidic cubic phase injector facilitates membrane protein serial femtosecond crystallography, Nat. Commun. 5 (2014) 3309.

[46] M.L. Verdonk, J.C. Cole, M.J. Hartshorn, C.W. Murray, R.D. Taylor, Improved protein-ligand docking using GOLD, Proteins 52 (2003) 609-623.

[47] G. Jones, P. Willett, R.C. Glen, A.R. Leach, R. Taylor, Development and validation of a genetic algorithm for flexible docking, J. Mol. Biol. 267 (1997) 727-748.

[48] L. Di Magno, D. Manzi, D. D’Amico, S. Coni, A. Macone, P. Infante, L. Di Marcotullio, E. De Smaele, E. Ferretti, I. Screpanti, E. Agostinelli, A. Gulino, G. Canettieri, Druggable glycolytic requirement for Hedgehog-dependent neuronal and medulloblastoma growth, Cell Cycle 13 (2014) 3404-3413.

[49] W. Shi, B.A. Nacev, B.T. Aftab, S. Head, C.M. Rudin, J.O. Liu, Itraconazole side chain analogues: structure-activity relationship studies for inhibition of endothelial cell proliferation, vascular endothelial growth factor receptor 2 (VEGFR2) glycosylation, and hedgehog signaling, J. Med. Chem. 54 (2011) $7363-7374$

[50] M.S. Christodoulou, M. Mori, R. Pantano, R. Alfonsi, P. Infante, M. Botta, G. Damia, F. Ricci, P.A. Sotiropoulou, S. Liekens, B. Botta, D. Passarella, Click reaction as a tool to combine pharmacophores: the case of Vismodegib, Chempluschem 80 (2015) 938-943.

[51] A. Lévai, Synthesis of isoflavones, J. Heterocycl. Chem. 41 (2004) 449-460.

[52] C. Ingallina, P.M. Costa, F. Ghirga, R. Klippstein, J.T. Wang, S. Berardozzi N. Hodgins, P. Infante, S.M. Pollard, B. Botta, K.T. Al-Jamal, Polymeric glabrescione B nanocapsules for passive targeting of Hedgehog-dependent tumor therapy in vitro, Nanomedicine 12 (2017) 711-728.

[53] Kristiina Wähälä, T.A. Hase, Expedient synthesis of polyhydroxyisoflavones, J. Chem. Soc., Perkin Trans. 1 (1991) 3005-3008.

[54] T. Sheng, S. Chi, X. Zhang, J. Xie, Regulation of Gli1 localization by the cAMP protein kinase A signaling axis through a site near the nuclear localization signal, J. Biol. Chem. 281 (2006) 9-12.

[55] X. Zhang, F. Zhao, Y. Wu, J. Yang, G.W. Han, S. Zhao, A. Ishchenko, L. Ye, X. Lin, K. Ding, V. Dharmarajan, P.R. Griffin, C. Gati, G. Nelson, M.S. Hunter M.A. Hanson, V. Cherezov, R.C. Stevens, W. Tan, H. Tao, F. Xu, Crystal structure of a multi-domain human smoothened receptor in complex with a super stabilizing ligand, Nat. Commun. 8 (2017) 15383.

[56] M. Lauth, V. Rohnalter, A. Bergstrom, M. Kooshesh, P. Svenningsson, R. Toftgard, Antipsychotic drugs regulate hedgehog signaling by modulation of 7-dehydrocholesterol reductase levels, Mol. Pharmacol. 78 (2010) 486-496.

[57] B. Al-Lazikani, U. Banerji, P. Workman, Combinatorial drug therapy for cancer in the post-genomic era, Nat. Biotechnol. 30 (2012) 679-692.

[58] G.R. Zimmermann, J. Lehar, C.T. Keith, Multi-target therapeutics: when the whole is greater than the sum of the parts, Drug Discov. Today 12 (2007) 34-42.

[59] P. Li, C. Huang, Y. Fu, J. Wang, Z. Wu, J. Ru, C. Zheng, Z. Guo, X. Chen, W. Zhou, W. Zhang, Y. Li, J. Chen, A. Lu, Y. Wang, Large-scale exploration and analysis of drug combinations, Bioinformatics 31 (2015) 2007-2016. 